\title{
PROCESSO DE INDUÇÃO DO PROFESSOR INICIANTE: o papel da coordenação pedagógica
}

\author{
Erica Cristina de Souza Sena ${ }^{1}$ \\ Fernanda Pinheiro Lopes Camacho² \\ Maria de Fátima Ramos de Andrade 3
}

\section{RESUMO}

Neste artigo, apresentamos um levantamento bibliográfico feito com o objetivo de se analisarem dissertações e teses que tratam do processo de indução do professor iniciante e o papel do coordenador pedagógico, nas bases da CAPES (Coordenação de Aperfeiçoamento de Pessoal de Nível Superior) e do IBICT (Banco de Teses do Instituto Brasileiro de Informação em Ciência e Tecnologia) do período de 2008 a 2019. Para tal, utilizamos os seguintes descritores: professor iniciante, indução pedagógica, vínculo, acolhimento, anos iniciais do Ensino Fundamental e coordenação pedagógica. Obtivemos, com isso, onze pesquisas. Para este estudo, procuramos identificar os objetivos, o referencial teórico, as metodologias utilizadas e os principais resultados consolidados nas pesquisas. Ao analisarmos os achados das pesquisas estudadas, constatamos a necessidade de ampliação dos programas e fomento aos de inserção e apoio ao professor iniciante nas Secretarias Municipais e Estaduais. As pesquisas em destaque evidenciaram que os processos de formação continuada, sejam nas unidades escolares ou ofertados pelas Secretarias de Educação, impactam a rotina, os saberes dos professores, contribuindo para a docência; demonstram também a preocupação com o ingresso do professor iniciante.

Palavras-chave: Processo de indução. Professor iniciante. Coordenador pedagógico.

\section{BEGINNING TEACHER'S INDUCTION PROCESS:}

the role of pedagogical coordination

\footnotetext{
1 Mestre em educação, Universidade Municipal de São Caetano (USCS). Prefeitura de Santo André- Brasil. Orcid iD: https://orcid.org/0000-0002-1778-074x. E-mail: ericacssena@gmail.com 2 Mestre em educação, Universidade Municipal de São Caetano (USCS). Prefeitura de Santo André- Brasil. Orcid iD: https://orcid.org/0000-0001-5519-8817. E-mail: fernandapinheirocamacho@gmail.com

3 Doutora em comunicação e semiótica, Pontifícia Universidade Católica de São Paulo (PUC/SP). Universidade Municipal de São Caetano e Universidade Presbiteriana Mackenzie Brasil. Orcid iD: https://orcid.org/0000-0003-4945-8752. E-mail: mfrda@uol.com.br
} 


\section{ABSTRACT}

In this article, we present a bibliographic survey with the intention of analyzing lectures and theses that deal with the induction process of the initiating professor and the role of the pedagogical coordinator, found on the repositories from CAPES (Coordination of Improvement of Higher Education Personnel) and IBICT (Thesis Bank of the Brazilian Institute of Information in Science and Technology) from 2008 to 2019. For this, we used the following descriptors: beginner teacher, pedagogical induction, bond, reception, initial years of Elementary School and pedagogical coordination. With that, we obtained eleven surveys. For this study, we seek to identify the objectives, the theoretical framework, the methodologies used and the main results consolidated in the research. When analyzing the findings of the researches studied, we found that there is a need for the expansion and foment of those programs that work with the insertion and support for the beginner teacher in the Municipal and State Secretariats. The highlighted researches showed that the processes of continuing education, whether in the school units or those offered by the Education Departments, impact the routine and knowledge of teachers, contributing to teaching; they also demonstrated the concern with the admission of the beginning teacher.

Keywords: Induction process. Beginning teacher. Pedagogical coordinator.

\section{INICIO DEL PROCESO DE INDUCCIÓN DEL PROFESOR:}

\section{el papel de la coordinación pedagógica}

\section{RESUMEN}

En este artículo se presenta un relevamiento bibliográfico realizado con el objetivo de analizar disertaciones y tesis que abordan el proceso de inducción del docente principiante y el rol del coordinador pedagógico, basado en CAPES (Coordinación para la Perfeccionamiento del Personal de Educación Superior) e IBICT (Banco de Tesis del Instituto Brasileño de Información en Ciencia y Tecnología) de 2008 a 2019. Para ello, se utilizaron los siguientes descriptores: maestro principiante, inducción pedagógica, vínculo, recepción, años iniciales de Educación Primaria y coordinación pedagógica. Con eso, obtuvimos once encuestas. Para este estudio, buscamos identificar los objetivos, el referente teórico, las metodologías utilizadas y los principales resultados consolidados en la investigación. Al analizar los hallazgos de las investigaciones estudiadas, notamos la necesidad de ampliar los programas y alentarlos a insertar y apoyar al docente principiante en las Secretarías Municipales y Estatales. Las investigaciones destacadas mostraron que los procesos de educación continua, ya sea en las unidades escolares $U$ ofrecidos por los Departamentos de Educación, impactan la rutina, el conocimiento de los docentes, contribuyendo a la enseñanza; también demuestran la preocupación por la admisión del maestro principiante.

Palabras clave: Proceso de inducción. Maestra principiante. Coordinador pedagógico. 


\section{INTRODUÇÃO}

O desenvolvimento profissional docente tem sido pauta de muitos estudos teóricos que tratam da importância de qualificar-se à docência. Nesse contexto, a formação inicial e a continuada ganham visibilidade e se mostram essenciais para os que iniciam a carreira. Os professores iniciantes na carreira docente são aqueles que concluíram a graduação e que ingressam nas unidades escolares, via concursos e contratações, atuando diretamente com os alunos. O processo de indução dos professores iniciantes é um período que possibilita articulações, parcerias efetivas com pares, e professores experientes, observações e análise de boas práticas, o acolhimento deste sujeito, quem é essa pessoa, quais caminhos e contribuições que carrega na construção da identidade profissional.

O objetivo deste estudo é, a partir do levantamento feito em dois bancos de teses e dissertações - IBICT e CAPES -, identificar e analisar o que foi produzido a respeito do processo de indução do professor iniciante e o papel do coordenador pedagógico (CP). O artigo está organizado da seguinte forma: na parte inicial, discorremos sobre desenvolvimento profissional docente e processo de indução. Na sequência, apresentamos o levantamento e a análise das pesquisas encontradas no catálogo de Teses e Dissertações da Capes que tratam da temática professor iniciante, processo de indução e o papel da coordenação pedagógica. Na parte final, tecemos algumas considerações a respeito do estudo realizado.

\section{DESENVOLVIMENTO PROFISSIONAL DOCENTE E PROCESSO DE INDUÇÃO: algumas considerações}

A palavra desenvolvimento remete a algo que evolui ou apresenta progressão. Quando falamos do desenvolvimento profissional docente falamos de um processo complexo e dinâmico, que se constitui em diferentes momentos da vida do professor, antes, durante e após a formação inicial, no contexto da formação continuada em serviço (NÓVOA, 2007). 
Segundo Marcelo Garcia (2009), o desenvolvimento profissional docente caracteriza-se como um processo de longo tempo, processo este que impulsiona o professor a buscar a qualificação do seu trabalho e que envolve diversas experiências, intencionais e planejadas. Em caminho similar, André (2010) defende que a profissionalização docente deve ser um aprendizado de longo prazo, individual ou coletivo, motivando esses sujeitos a refletir sobre a sua prática em sala de aula e permitindo mudanças efetivas em seus espaços de atuação.

É importante que as instituições escolares estejam preparadas para acolher e olhar cuidadosamente a integração desses profissionais, que acabam criando mecanismos de sobrevivência e defesa para realizar a sua jornada. Sabemos que o professor terá um percurso longo na carreira, o que nos coloca diante da necessidade de uma formação permanente nas escolas, oferecidas pela rede de ensino, pelas equipes gestoras, no contexto da própria escola, em espaços formais de reuniões, sendo elas individuais e coletivas para a contínua teorização da prática.

Para que os professores iniciantes se sintam acolhidos, orientados e valorizados em seus conhecimentos, o trabalho de formação continuada deve se vincular a uma perspectiva sistêmica, na qual toda a comunidade escolar se comprometa com o seu desenvolvimento profissional, pois:

Ensinar é um trabalho complexo, que requer conhecimento, autonomia, autoria, prazer e criatividade. O desafio está justamente em como criar condições para formar profissionais com tais competências, sem cair na tentação de sistematizar tudo e transformá-los em cumpridores de tarefas (CARDOSO; PEREZ, 2012, p. $15)$.

Nesse sentido, o acompanhamento, a avaliação e a reflexão das práticas desse professor são fundamentais para 0 seu engajamento profissional, favorecendo a sua construção de conhecimentos, o alcance de melhorias e a consolidação de mudanças significativas em sua prática docente. Os espaços formativos constituídos no interior das Unidades Escolares são determinantes para o desenvolvimento profissional, uma vez que os momentos de trocas no coletivo e a convivência com parceiros mais 
experientes possibilitam ao professor iniciante vivenciar novos saberes e ampliar seu repertório de práticas (NÓVOA, 2009).

O período de indução pode ser confundido com o estágio ou período probatório, porém são processos distintos: a "[...] indução põe a ênfase no desenvolvimento da competência profissional enquanto o de probatório se destina a provar a existência da competência" (ALARCÃO; ROLDÃO, 2014, p. 113).

As contribuições de Wong (2004) apontam que a comunidade escolar deve estar engajada neste processo de indução. O programa permite sustentação se for uma comunidade de aprendizado de todos os envolvidos, do professor iniciante, do experiente, de modo que as contribuições sejam respeitadas e valorizadas, com um plano elaborado e permanente, que alcance o avanço na aprendizagem dos alunos.

[...] provável que os professores aprovados optem por trabalhar nas escolas quando houver uma "massa crítica" de colegas que compartilham o mesmo compromisso com desempenho do aluno e onde o diretor é a chave para estabelecer esse compromisso com a melhoria do professor e o desempenho dos alunos (WONG, 2004, p. 18).

Segundo Reis (2015) o programa de indução deve ser permanente. Seria necessário que todos os professores, independentemente dos anos de exercício da profissão, tenham o olhar voltado para a aprendizagem e a observação dos trabalhos de seus colegas - interagindo, opinando como comunidades educativas que consolidam saberes e se comprometem com a formação de todos os sujeitos.

\section{O ACOLHIMENTO DO CP AO PROFESSOR INICIANTE E A CONSTITUIÇÃO DE VÍNCULOS}

Coordenar um grupo ou uma instituição não é uma tarefa fácil, especialmente, com tantas demandas que vão além das questões pedagógicas. Assim, é importante que O CP consiga se desvencilhar de atividades que o desviam do foco de sua atuação, pois ele não pode 
perder de vista o seu papel de articulador, formador e transformador (GOUVEIA; PLACCO, 2013).

Neste processo, o olhar para a pessoa, uma das características fundamentais, de um CP é essencial: permite enxergar saberes, fragilidades e mudanças. Importante o coordenador pedagógico ter a amplitude do olhar que permite ir ao encontro dos sujeitos.

A escuta é outra parceira neste caminhar. Esquecida nos tempos atuais, também evidencia o despojamento da pessoa na função que exerce. Os estudos de Rogers ressaltam a importância de ouvir o outro,

Quando digo que gosto de ouvir alguém estou me referindo evidentemente a uma escuta profunda. Quero dizer que ouço as palavras, os pensamentos, a tonalidade dos sentimentos, o significado pessoal, até mesmo o significado que subjaz às intenções do interlocutor (ROGERS, 1983, p. 5 apud ALMEIDA, 2012 p. 72).

O ato de escutar também se apresenta como um desafio na rotina do CP; as demandas podem sufocar a necessidade de ouvir e de ser ouvido, pois dentro desse sujeito "mora uma pessoa", assim também acontece com o professor - "[...] todo professor mora dentro de uma pessoa, todo aluno mora também e só esta consciência amorosa pode salvar a escola" (SOLIGO, s/d).

A escuta profunda, que transpassa o ato de ouvir, possibilita, na sala de aula, tanto a aprendizagem significativa e afetiva aos alunos, como também propicia uma relação mais consistente entre o professor e o coordenador pedagógico, no processo de constituição de vínculo.

Por qual espécie de processo pode ser desenvolvida essa abertura à mudança? Um dos conceitos que pode abrir o caminho para responder estas questões, é o conceito de "aprendizagem significativa" ou "aprendizagem experimental". Por estas palavras eu quero significar o tipo de aprendizagem que envolve a pessoa como um todo, em seus aspectos cognitivos e afetivos. É a aprendizagem na qual a pessoa se envolve. É a aprendizagem auto iniciada. A aprendizagem que promove uma diferença no comportamento do indivíduo, no curso de ações que ele escolhe para o futuro, em suas atitudes e em sua personalidade (ROGERS, 1997, p. 259). 
O CP precisaria ter o olhar atento, a escuta ativa, assim como uma boa comunicação que mostra e transmite significados ao professor, pois este processo de conhecer e valorizar as miudezas das relações interpessoais, permitiria que o professor também a valorizasse e pudesse vir a desenvolver atitudes semelhantes aos seus alunos. Neste exercício de olhar, escutar e falar, "[...] é possível diagnosticar suas necessidades, sentir suas angústias e oferecer a ele a ajuda de que ele precisa naquele momento, o que pode ser feito por indicação de ações e de leituras, intermediação na troca de expectativas, encaminhamentos diversos" (ALMEIDA, 2012, p. 75).

Estar na função de coordenador pedagógico e de professor, a reflexão e a atuação da fala permitem o reconhecimento e conhecimento de suas funções exercidas no processo de ensino e aprendizagem. "Se a relação pedagógica é a relação professor-aluno-conhecimento, a relação do coordenador pedagógico com o professor também é pedagógica, porque é mediada pelo conteúdo da formação" (ALMEIDA, 2012, p. 75).

Ninguém nasce professor ou coordenador pedagógico. O desenvolvimento profissional de ambos acontece no dia a dia, no espaço escolar, nas vivências do coletivo, nas aprendizagens, no planejamento articulado com as necessidades individuais e coletivas. E nos tropeços no caminho.

\section{O QUE ENCONTRAMOS NAS PESQUISAS}

Primeiramente, iniciamos o trabalho de varredura utilizando a Biblioteca Digital de Teses e Dissertações - do Instituto Brasileiro de Informações, Ciências e Tecnologia - IBICT. Posteriormente, consultamos a plataforma da Coordenação de Aperfeiçoamento de Pessoal de Nível Superior - CAPES. Assim, identificamos onze estudos de produções científicas que tratam da temática professor iniciante, processo de indução, coordenador pedagógico no contexto dos Anos Iniciais do Ensino Fundamental.

A seguir, apresentamos um quadro com as pesquisas correlatas encontradas, articulando e analisando os achados dos pesquisadores. 
Quadro 1 - Pesquisas correlatas

\begin{tabular}{|c|c|c|}
\hline $\begin{array}{c}\text { Ano / } \\
\text { Universidade/ } \\
\text { Modalidades }\end{array}$ & $\begin{array}{l}\text { Nome do } \\
\text { pesquisador }\end{array}$ & Título do trabalho \\
\hline $\begin{array}{l}2019 \text { - Doutorado } \\
\text { Pontifica } \\
\text { Universidade } \\
\text { Católica de São } \\
\text { Paulo }\end{array}$ & Nay & $\begin{array}{l}\text { Formação Continuada e } \\
\text { desenvolvimento profissional de } \\
\text { professores da educação } \\
\text { básica que participam de um } \\
\text { programa de inserção } \\
\text { profissional }\end{array}$ \\
\hline $\begin{array}{l}2018 \text { - Mestrado } \\
\text { Universidade } \\
\text { Federal de São } \\
\text { Paulo Escola De } \\
\text { Filosofia, Letras e } \\
\text { Ciências Humanas }\end{array}$ & $\begin{array}{l}\mathrm{Ca} \\
\text { Arai }\end{array}$ & $\begin{array}{lll}\text { Implicações de programas } & \text { de } \\
\text { iniciação à docência } & \text { na } \\
\text { inserção } & \text { profissional } & \text { de } \\
\text { professores } & & \end{array}$ \\
\hline $\begin{array}{l}2018 \text { - Mestrado } \\
\text { Universidade } \\
\text { Estadual de São } \\
\text { Paulo - Rio Claro }\end{array}$ & $\begin{array}{l}\text { Tagiane } \\
\text { dos } \\
\text { Bete }\end{array}$ & $\begin{array}{l}\text { A professora coordenadora na } \\
\text { educação infantil: } \\
\text { composição da organização do } \\
\text { trabalho pedagógico e da } \\
\text { formação dos educadores }\end{array}$ \\
\hline $\begin{array}{l}2017 \text { - Mestrado } \\
\text { Universidade } \\
\text { Estadual de Mato } \\
\text { Grosso do Sul }\end{array}$ & $\begin{array}{l}\text { Daniella Cristini } \\
\text { Fernandes da } \\
\text { Silva }\end{array}$ & $\begin{array}{l}\text { O papel do coordenador } \\
\text { pedagógico na socialização do } \\
\text { professor iniciante na rede } \\
\text { municipal de Andradina-SP }\end{array}$ \\
\hline $\begin{array}{l}2017 \text { - Mestrado } \\
\text { Universidade } \\
\text { Federal de Santa } \\
\text { Maria }\end{array}$ & $\begin{array}{r}\mathrm{Pa} \\
\text { Mall } \\
\text { Schn }\end{array}$ & $\begin{array}{l}\text { Possibilidades de } \\
\text { acompanhamento pedagógico } \\
\text { de professores iniciantes frente } \\
\text { aos desafios do trabalho em um } \\
\text { instituto federal de educação, } \\
\text { ciência e tecnologia }\end{array}$ \\
\hline $\begin{array}{l}2017 \text { - Doutorado } \\
\text { Pontifícia } \\
\text { Universidade } \\
\text { Católica de São } \\
\text { Paulo }\end{array}$ & Rod & $\begin{array}{l}\text { O desenvolvimento profissional } \\
\text { de um grupo de coordenadoras } \\
\text { pedagógicas iniciantes: } \\
\text { movimentos e indícios de } \\
\text { aprendizagem coletiva, a partir } \\
\text { de uma pesquisa-formação }\end{array}$ \\
\hline $\begin{array}{l}\text { 2016-Doutorado } \\
\text { Universidade } \\
\text { Estadual de São } \\
\text { Paulo }\end{array}$ & Marina Cyrino & $\begin{array}{l}\text { Do acolhimento ao } \\
\text { acompanhamento } \\
\text { compartilhado: a construção } \\
\text { colaborativa de uma proposta } \\
\text { para o estágio curricular no } \\
\text { curso de Pedagogia }\end{array}$ \\
\hline $\begin{array}{l}2016-\text { Mestrado } \\
\text { Pontifícia }\end{array}$ & $\begin{array}{r}M c \\
\mathrm{Cazz} \\
\end{array}$ & $\begin{array}{l}\text { O Tempo, o Caminho e a } \\
\text { Experiência do Coordenador }\end{array}$ \\
\hline
\end{tabular}




\begin{tabular}{|c|c|c|}
\hline $\begin{array}{l}\text { Universidade } \\
\text { Católica de São } \\
\text { Paulo }\end{array}$ & & $\begin{array}{l}\text { Pedagógico da Creche: as } \\
\text { rotinas e os saberes que } \\
\text { articulam, formam er e } \\
\text { transformam suas práticas } \\
\text { educacionais }\end{array}$ \\
\hline $\begin{array}{l}2014-\text { Mestrado } \\
\text { Universidade } \\
\text { Federal de Mato } \\
\text { Grosso }\end{array}$ & $\begin{array}{l}\text { Mendes Solange } \\
\text { Lemes da Silva }\end{array}$ & $\begin{array}{l}\text { Práticas formativas em } \text { Mato } \\
\text { Grosso sob o olhar de } \\
\text { professores iniciantes }\end{array}$ \\
\hline $\begin{array}{l}2014 \text { - Doutorado } \\
\text { Pontifícia } \\
\text { Universidade } \\
\text { Católica de São } \\
\text { Paulo }\end{array}$ & $\begin{array}{l}\text { Andrea Jamil } \\
\text { Paiva Mollica }\end{array}$ & $\begin{array}{l}\text { O professor especialista } \\
\text { iniciante: contribuições do } \\
\text { coordenador pedagógico para } \\
\text { seu trabalho }\end{array}$ \\
\hline $\begin{array}{l}2013 \text { - Mestrado } \\
\text { Universidade } \\
\text { Federal de São } \\
\text { Carlos }\end{array}$ & $\begin{array}{l}\text { Roger Eduardo } \\
\text { Silva Santos }\end{array}$ & $\begin{array}{l}\text { Formação de professores que } \\
\text { ensinam matemática nos anos } \\
\text { iniciais: contribuições do } \\
\text { Programa Institucional de Bolsas } \\
\text { de Iniciação à Docência (PIBID) } \\
\text { na UFSCar }\end{array}$ \\
\hline
\end{tabular}

Fonte: As autoras (2020).

Iniciamos a análise com a pesquisa de doutorado de Marina Cyrino Do acolhimento ao acompanhamento compartilhado: a construção colaborativa de uma proposta para o estágio curricular no curso de Pedagogia. Nela, a pesquisadora apresenta uma análise realizada no curso de licenciatura em Pedagogia da UNESP, campus de Rio Claro. Teve como objeto de pesquisa o estágio de prática de ensino nos anos iniciais do Ensino Fundamental, tendo como referência o acompanhamento dos estagiários, profissionalização docente e a formação inicial de professores.

A pesquisa traz o olhar do professor para a necessidade de acolhimento do estagiário, sendo um principiante capaz de aprender, compreender as diversas faces da rotina escolar, do trabalho da docência, contribuindo com a sua experiência neste processo (CYRINO, 2016).

Essa investigação ocorreu em seis escolas municipais e em uma universidade, sendo uma pesquisa qualitativa construtivo-colaborativa. Os dados analisados demonstraram que ocorreu um processo de acolhimento para o acompanhamento de estagiários; os instrumentos utilizados 
ofereceram um papel formalizado e sistematizado ao professor da escola. As professoras-parceiras sinalizaram relativa responsabilidade na formação dos estagiários.

Presumindo uma relação de parceria com a escola, os dados obtidos mostram que se faz necessária a análise de práticas, a necessidade de o adulto estar engajado e comprometido no processo de aprendizagem e a disposição de um professor-parceiro para acompanhar esse professor iniciante neste processo (CYRINO, 2016).

Para Cyrino, (2016), o processo de parceria entre a universidade e escola "[...] pressupõe que ambas as instituições e seus atores assumam um compromisso, formalizado e pessoal na preparação de seus futuros profissionais" (CYRINO, 2016, p. 74).

O estudo de Santos ocorreu em 2013, na modalidade de mestrado pela UFSCAR, com o título "Formação de professores que ensinam matemática nos anos iniciais: contribuições do Programa Institucional de Bolsas de Iniciação à Docência (PIBID) na UFSCar". Segundo Santos (2013), a pesquisa teve uma abordagem qualitativa, do tipo analítico e interpretativo, investigando as contribuições do processo de formação docente em parceria com o PIBID/UFSCar. Participaram do estudo, quatro bolsistas do programa com o projeto de jogos matemáticos, alunos do curso de Licenciatura em Pedagogia pela universidade citada.

Ainda, segundo Santos, o estudo buscou analisar as reflexões e sentimentos dos futuros professores que compõem o projeto e suas vivências no trabalho escolar no Ensino Fundamental. Os referenciais teóricos utilizados citados em relação à formação inicial de professor foram os estudos de Marcelo Garcia (1998, 1999); quanto aos saberes docentes, foram mencionados Mizukami e Reali (2005); Tardif (2008); Gauthier (1998); quanto ao início da docência, foi mencionado Huberman (1995); e sobre os conteúdos matemáticos e didático-pedagógicos Grando (2004) e Passos (2009).

Os resultados revelaram que foram poucas compreensões referentes ao ensino de matemática nas séries iniciais do ensino fundamental. Quanto 
ao processo de formação inicial desses professores, fizeram-se presentes, não só o sentimento de parceria, acolhimento e pertenças como também aqueles declarados na literatura. Assim, evidenciou-se a necessidade de investimento na formação inicial e no ensino na área de matemática (SANTOS, 2013).

Roncon (2018), em sua pesquisa Implicações de programas de iniciação à docência na inserção profissional de professores, pela Universidade Federal de São Paulo, Escola de Filosofia, Letras e Ciências Humanas, utilizou a abordagem qualitativa, aplicando questionários e realizando entrevista e análise documental. A pesquisa contou com os referenciais teóricos para os estudos referentes à inserção profissional docente - Garcia (1999); Mizukami (1996) e Nóvoa (1995).

Segundo Roncon (2018), seu estudo teve como objetivo conhecer e analisar as ações dos Programas de iniciação à docência, dentre estes, a Residência Pedagógica e o Programa Institucional de Bolsas de Iniciação à Docência.

Os programas de inserção profissional docente ocorreram no curso de graduação de Pedagogia, com estágio, ofertado pela Universidade Federal de São Paulo - UNIFESP, em parcerias com algumas escolas públicas conveniadas com a instituição.

Roncon (2018) mostra que o início de carreira docente é uma etapa desafiadora, evidenciando as inquietações do período de transição da vida de estudante para a de professor. Os resultados obtidos na pesquisa revelaram que a formação consolidada no curso de Pedagogia, o Programa Institucional de Bolsas de Iniciação à Docência e a Residência Pedagógica contribuíram para com a inserção profissional, mesmo perante alguns desafios vivenciados diante dos conflitos internos e externos com a cultura escolar excludente.

A dissertação de mestrado Práticas formativas em Mato Grosso sob o olhar de professores iniciantes, realizada por Silva (2014), pela Universidade Federal de Mato Grosso, investigou as práticas formativas educacionais desenvolvidas por meio da Formação Continuada da SEDUC-MT, SEMED/RO 
e de escolas particulares do município de Rondonópolis-MT, em seu trabalho de acolhimento e de ação ao professor egresso do curso de Pedagogia, focando também em como estas ações contribuíram para os desafios enfrentados nas experiências iniciais da docência (SILVA, 2014).

De acordo com Silva (2014), o trabalho apresentado utilizou a abordagem qualitativa: os instrumentos foram a análise documental, questionário e entrevistas. Participaram da pesquisa seis professores iniciantes que foram os sujeitos da pesquisa, e alguns colaboradores: coordenadores, gestores e mediadores da formação das escolas públicas e particulares.

Os dados investigados evidenciaram que as formações continuadas nas redes estaduais e municipais de ensino não apresentam o enfoque para a formação do professor iniciante; duas escolas da rede municipal possuem o acompanhamento para $\mathrm{o}$ professor iniciante por participarem de um projeto de pesquisa do Programa Observatório da Educação - OBEDUC - , parceria entre a Capes e o INEP. As duas escolas da rede privada investigadas não possuem formação continuada; o momento ofertado constitui em encontros para resolução de dúvidas e orientações.

Schneiders (2017) realizou a pesquisa de mestrado intitulada Possibilidades de acompanhamento pedagógico de professores iniciantes frente aos desafios do trabalho em um instituto federal de educação, ciência e tecnologia na Universidade Federal de Santa Maria - UFSM.

De acordo com Schneiders, a investigação teve como objetivo o acompanhamento pedagógico de professores iniciantes no Instituto Federal de Educação, Ciência e Tecnologia e o acolhimento destes professores no Campus Panambi. A pesquisa contou com a abordagem qualitativa e com os referenciais teóricos para relatar os desafios vivenciados pela escola Canário (2006); Santos (2011); o trabalho docente Tardif; Lessard (2005); O professor iniciante, Garcia (2009); Huberman (2000); Tardif (2002) e Imbernón (1998); o papel do coordenador pedagógico na rotina escolar Placco; Almeida e Souza (2011);

Os resultados obtidos em sua pesquisa apontaram que os professores não consideram a vivência pelas diferentes modalidades de ensino como 
um desafio, mas sim como possibilidade de construir novos saberes com diversos públicos. No campus Panambi, local em que ocorreu a pesquisa, não houve formação para qualificação dos docentes nem para a acolhida dos professores iniciantes. Assim, cada docente teve autonomia para construir seu percurso formativo; foi a cultura local a referência para ele realizar seu trabalho.

Por sua vez, as informações obtidas do trabalho do Setor do Apoio Pedagógico - SAP - concluem que a função do CP acaba por ser de um organizador de atividades burocráticas e administrativas e não realizam a sua função, que seria evidenciar as questões pedagógicas, fundamentar as diretrizes e o trabalho deste setor contribuindo para a atuação do professor iniciante.

O estudo de Mollica (doutorado) O professor especialista iniciante: contribuições do coordenador pedagógico para seu trabalho ocorreu em 2014 pela instituição PUC. A pesquisa utilizou a abordagem qualitativa e, para coletar os dados, realizou entrevistas com dois coordenadores pedagógicos e três professores iniciantes.

Segundo Mollica (2014), o trabalho teve como objetivo investigar quais as ações realizadas pelo Coordenador Pedagógico para contribuir com a docência do professor iniciante no contexto escolar e na sua prática pedagógica. Assim, verificou o docente iniciante de carreira e a função do Coordenador Pedagógico, evidenciando a dimensão afetiva. Como base teórica, os estudiosos que tratam deste assunto, no tocante aos fundamentos de Henri Wallon.

Os dados investigados relataram que o docente iniciante ao iniciar na Unidade Escolar não se sente pertencente ao espaço, por não conhecer os seus pares, o trabalho e, também, pelas dúvidas que surgem referentes à profissão. Surgem diversos sentimentos que prejudicam seu exercício (MOLLICA, 2014).

Ainda com Mollica, o estudo relata que o Coordenador Pedagógico pode, em sua função de possibilitar espaços nas reuniões pedagógicas para promover a unidade do grupo, compreender quais são as lacunas para a 
integração deste professor iniciante especialista, juntamente com todos os profissionais da escola, e planejar reuniões formativas conforme a necessidade do seu grupo. Os resultados obtidos indicam o investimento na formação do docente especialista no início da carreira com o propósito de contribuir com ações que o auxiliem no início do seu percurso profissional.

Silva (2017), em sua pesquisa de mestrado Papel do coordenador pedagógico na socialização do professor iniciante na rede municipal de Andradina-SP, pela Universidade Estadual de Mato Grosso do Sul - UEMS analisou as ações da coordenação pedagógica, entendendo-a como mediadora no ingresso do professor iniciante. Investigou quais desafios estes profissionais encontram no início da docência. Buscou conhecer também a formação continuada em serviço nas escolas de ensino fundamental da rede municipal de Andradina - SP.

De acordo com Silva (2017), a pesquisa utilizou a abordagem qualitativa como também fez $\mathrm{O}$ uso de questionários, grupo focal e entrevistas. Os sujeitos foram três coordenadores pedagógicos e três professoras com menos de três anos de docência. Constituíram o referencial teórico, os estudos de Marcelo Garcia (2009), Veenman (1988), Huberman (1992), Dubar (1997), Bardin (1977), Brito e Leonardos (2001).

Os resultados desvelaram que as intervenções realizadas pelo coordenador pedagógico na socialização e nas intervenções com os professores iniciantes de carreira, contribuíram no processo de indução. Demonstraram a importância da função do coordenador, que é referência no espaço escolar. Os encontros de formação realizados pela coordenação e as relações com os professores na unidade escolar colaboraram para resolução dos desafios enfrentados no início da docência.

O estudo de Beteghelli, realizado em 2018, intitulado A professora coordenadora na educação infantil: na composição da organização do trabalho pedagógico e da formação dos educadores, pela UNESP, Rio Claro na modalidade de Mestrado foi realizada na e com uma escola pública de educação infantil do município de Rio Claro/SP. O objetivo geral da investigação consistiv em compreender a articulação e o trabalho do CP no 
acompanhamento, na organização da rotina escolar, o seu desdobramento nas relações com os sujeitos, dificuldades e saberes vivenciados neste espaço constituído por um professor coordenador iniciante.

Trata-se de uma pesquisa narrativa. Os dados foram construídos a partir das escritas elaboradas por três professoras, por duas agentes educacionais e pela professora coordenadora. Foram utilizados os documentos da escola: Proposta Pedagógica, Plano de Trabalho da professora coordenadora, atas de reuniões pedagógicas em horários de Trabalho Pedagógico Coletivo e nos horários de Trabalho Pedagógico Individual.

As informações obtidas por meio dos resultados revelaram a plausibilidade do CP como formador da escola, e a importância de se considerarem as relações no trabalho. Surgiram divergências nos encontros de formação realizados, pois não consideraram as especificidades dos sujeitos e das limitações referentes ao contexto da rotina escolar. Os espaços destinados ao diálogo não garantiram a sua função. Foram encontrados desafios referentes às relações, tais como a escuta que não foi vivenciada como um elemento motivador entre o acolhimento e a constituição de parcerias.

A pesquisa de Sula (2016) O Tempo, o Caminho e a Experiência do Coordenador Pedagógico da Creche: as rotinas e os saberes que articulam, formam e transformam suas práticas educacionais, realizada no mestrado profissional pela instituição PUC-SP, revelou saberes relevantes constituídos pelos CP da creche, nos caminhos vivenciados na função, enquanto articuladores e formadores.

Segundo Sula, a pesquisa foi qualitativa e do tipo etnográfico; apresentou o objetivo de enunciar os saberes do CP que desempenha a função, nas creches da Rede Municipal de Santo André, baseado nas rotinas, articulações, ações formadoras e transformadoras no espaço escolar. Os instrumentos utilizados para coletas de dados foram os questionários e entrevistas. Os dados obtidos fundamentaram a caracterização dos sujeitos. Participaram da entrevista, quatro CP. 
O estudo contou com a contribuição dos referenciais teóricos de Almeida (2004, 2009, 2010), Placco (2006, 2010, 2012), Souza (2012, 2013), Tardif (2001), Vasconcellos (2010), entre outros. Os dados coletados revelaram que os coordenadores pedagógicos da rede estão no processo de constituição de sua função. As entrevistas realizadas, embora mostrassem que os sujeitos da pesquisa tinham uma rotina planejada do acompanhamento pedagógico, apresentou fragilidades pelas variações do dia a dia e os desafios no planejamento e estudo das ações formativas.

Quanto aos coordenadores pedagógicos, evidenciou-se que buscam novos saberes, valorizam a construção do trabalho coletivo, realizam a mediação de conflitos, a escuta, o falar e o olhar. Evidenciaram a importância da constituição do grupo, destacando que as relações interpessoais são os maiores desafios, bem como desassociar a creche de ações meramente assistencialistas, fundamentando-as em rotinas educacionais (SULA, 2016). Entre os demais aspectos mencionados, destacaram-se também o saber da historicidade e os saberes experienciais que constituem a identidade profissional e a profissionalização docente (SULA, 2016).

A dissertação de doutorado Formação continuada e desenvolvimento profissional de professores da educação básica que participam de um programa de inserção profissional, realizada por Telles, pela PUC, em 2019, teve como objetivo analisar o Programa de Tutoria Educacional ofertado aos professores iniciantes pela Secretaria Municipal de Educação de Manaus-AM e as contribuições para o Desenvolvimento Profissional desses profissionais que estavam iniciando a carreira.

O programa atende aos docentes em estágio probatório na rede municipal, independentemente de possuírem ou não experiências no ensino. $O$ interesse em estudar o programa ocorreu com a finalidade de conhecer as boas práticas e de compreender ações de indução para o professor iniciante.

Telles (2019) utilizou a abordagem qualitativa; para a coleta de dados foram usados os procedimentos de entrevista e observação, bem como a 
análise documental. As entrevistas ocorreram com gestores, coordenadores, professores formadores (tutores), professores iniciantes (tutorados) do município e a observação de três sessões de tutorial.

As informações obtidas por meio dos dados mostraram uma avaliação positiva do programa pelos sujeitos da pesquisa. Os gestores revelaram que é necessário para a construção de uma proposta de Formação Continuada para os docentes iniciantes - a validação da formação dos professores, a construção de matrizes de competência, o espaço para a discussão do estágio probatório e o processo de avaliação dos docentes do município (TELLES, 2019).

Para Telles (2019), os pontos negativos revelados pela pesquisa dizem respeito ao deslocamento e à logística dos formadores para as escolas. Quanto aos pontos positivos, a formação é voltada para aprendizagem dos alunos, e os resultados são visualizados no comportamento e nos saberes. Os professores iniciantes relataram a importância da parceria efetiva, orientações oferecidas pelos tutores e os espaços para reflexão da prática.

Os formadores (tutores) evidenciaram a necessidade de maior investimento para o tempo dos encontros de formação, um espaço próprio para a sua realização, a tutoria ser apenas para os docentes em estágio probatório e a falta de um acompanhamento dos professores que não fazem mais parte do programa.

Por sua vez, o trabalho mostra que o Programa de Tutoria Educacional embora tenha contribuído para o ingresso dos professores iniciantes da rede, ainda são necessárias ações efetivas e colaborativas na unidade escolar, entre os pares e o investimento na ampliação da tutoria para as equipes gestoras.

A pesquisa de doutorado de Pereira $O$ desenvolvimento profissional de um grupo de coordenadoras pedagógicas iniciantes: movimentos e indícios de aprendizagem coletiva, a partir de uma pesquisa-formação, realizada na PUC em 2017, investigou um grupo de coordenadoras pedagógicas iniciantes da rede municipal da Grande São Paulo, com o objetivo de 
elaborar e compor coletivamente uma proposta de formação e analisar o planejamento das ações formativas desse grupo (PEREIRA, 2017).

De acordo com Pereira, (2017) trata-se de uma pesquisa-formação conduzida na pesquisa-ação. A coleta de dados foi a transcrição de uma roda de conversa, com o registro audiografado de 16 encontros quinzenais de formação, no período de 10 meses, bem como a elaboração de um diário de campo. A análise dos dados foi baseada na análise de prosa e os dados revelaram que a formação coletiva contribuiu para o engajamento não só na sua função de coordenação pedagógica como também na de formadora. Identificaram-se desafios enfrentados no planejamento do trabalho, nos referenciais de atuação, nos espaços para realização de estudos, na clareza da função pelo olhar de outros profissionais da escola. Os pontos positivos foram a construção de um processo formativo centrado no exercício dos coordenadores iniciantes, fortalecendo assim o grupo de participantes. O trabalho indica que os sujeitos da pesquisa se legitimam na condição de formadores quando, em sua rotina, conseguem viver momentos de diálogos, de reflexão a respeito das práticas pedagógicas com o seu grupo de professores.

A seguir, apresentamos algumas considerações gerais acerca dos estudos correlacionados.

\section{ALGUMAS CONSIDERAÇÕES}

Analisando os aspectos decorrentes das pesquisas correlatas, destacamos especificidades nos trabalhos que apontaram alguns aspectos que buscamos explorar no tocante ao acolhimento do professor iniciante, aos processos de indução pedagógica e o papel do coordenador pedagógico.

De modo geral, a varredura realizada revelou a existência de diversos estudos relacionados a professores iniciantes que estão na graduação, especialistas, assim como a coordenadores pedagógicos iniciantes, evidenciando que a temática tem se mostrado cada vez mais necessária e urgente à realidade escolar. 
As diferentes instituições envolvidas explicitam também o interesse pelo tema em distintas comunidades acadêmicas. Salientamos a preocupação dos estudiosos, dos grupos de pesquisa e de algumas universidades quanto à inserção do professor iniciante na escola, após a conclusão da graduação, ao acolhimento na Unidade Escolar, à iniciação à docência e ao desenvolvimento profissional docente. Importa muito que esses processos sejam cuidados, analisados de uma maneira singular. Buscamos, ao longo da pesquisa, à luz do referencial teórico adotado que os processos de indução pedagógica podem e devem ser ainda mais investigadas.

Observamos que as pesquisas envolveram o professor iniciante nos anos iniciais do Ensino Fundamental, também na primeira infância, no tocante ao seu desenvolvimento profissional.

Neste caminho, os estudos de Mollica (2014) e Silva (2014) trouxeram o olhar do quanto se faz necessário investir no professor iniciante, nas ações formativas e pedagógicas, no processo de indução e nas relações com os demais educadores. Trouxeram também elementos para a compreensão do professor nos desafios vivenciados nos anos iniciais da docência em sua prática pedagógica e a importância da atuação do coordenador pedagógico neste percurso, salientando a dimensão afetiva e 0 acolhimento.

Assim também o trabalho de Telles (2019) relata as vivências do professor iniciante na educação básica, evidenciando as boas práticas, compreendendo quais são as ações de indução para o professor iniciante. Schneiders (2017) embora tenha evidenciado o acolhimento dos professores iniciantes e como foram acompanhados, mostra que o estudo ocorreu com professores na graduação.

Em relação às pesquisas que evidenciaram o papel, os saberes que permeiam a função do coordenador pedagógico, puderam ser identificados os desafios deste profissional na rotina escolar, a importância de sua atuação para o desenvolvimento profissional dos professores e a necessidade do investimento na constituição de vínculos. 
De modo geral, as ações formativas confirmam a importância da reflexão sobre práticas docentes e coletivas assim como o cuidado nas relações com os sujeitos, sendo a escuta ativa e a boa comunicação condições favorecedoras das relações interpessoais. Esses apontamentos poderão trazer contribuições para pesquisas quanto ao professor iniciante e seu acolhimento, decorrente dos dados coletados e da sua análise, dentre estes os estudos de Sula (2016), Pereira (2017), Beteghelli (2018) e Silva (2017).

O referencial teórico utilizado em relação à formação inicial de professor foram os estudos de Marcelo Garcia (1998, 1999); quanto aos saberes docentes, estiveram mencionados Mizukami e Reali (2005); Tardif (2008); Gauthier (1998); em relação ao início da docência, Huberman (1995); e sobre os conteúdos matemáticos e didático-pedagógicos, Grando (2004) e Passos (2009).

Ao analisar os achados das pesquisas estudadas, constatamos a necessidade de ampliação dos programas de inserção e apoio ao professor iniciante nas secretarias municipais e estaduais. As pesquisas, em destaque, evidenciaram que os processos de formação continuada tanto nas unidades escolares quanto ofertados pelas Secretarias de Educação impactam na rotina, nos saberes dos professores, contribuindo com a docência. Demonstram, além disso, a preocupação com o ingresso do professor iniciante.

No tocante aos processos de indução pedagógica, os estudos evidenciam a relevância de ações de alguns programas de tutorias e estágios, em parceria com as Secretarias de Educação e as Universidades. Neste sentido, destacamos a importância da concretização dessa ação, com o investimento de políticas públicas, assim como o monitoramento desses programas, vinculados às Secretarias de Educação.

As pesquisas em foco tangenciam os aspectos da formação em trabalho. Acreditamos, todavia, que haja a necessidade de aprofundamento das reais necessidades formativas de quem se inicia na profissão, como o conhecimento da prática e o conhecimento pedagógico de conteúdo são constituídos, e principalmente, como esses saberes afetam 
a aprendizagem dos alunos. A participação do professor iniciante nos processos formativos, nas trocas com os pares e na análise da prática pode ainda ser melhor explorada. No que tange a coordenação pedagógica, os estudos evidenciam a importância dessa função, suas ações e contribuições com a rotina escolar.

Schneiders (2017) coloca em evidência o trabalho do CP. Aponta os desafios de sua rotina escolar, os enfrentamentos em sua função formativa e o acompanhamento do trabalho docente. Seus estudos revelam que a função dos CP, permeia diversas atividades rotineiras, na resolução dos desafios com os alunos, as famílias e as questões burocráticas da escola.

Os estudos de Mollica (2014), Sula (2016) e Pereira (2017) trouxeram elementos que revelaram a complexidade da função do CP, bem como a sua atuação formativa na escola em busca de novos saberes.

As mudanças exigem um esforço de consciência dos CP em se perceberem como sujeitos adultos em constante aprendizagem. A busca de novas interações, o trabalho colaborativo, as aprendizagens coletivas, a constituição dos vínculos, constituem um desafio permanente para o qual se fazem necessários diversos saberes (SULA, 2016, p. 56).

Trazemos o olhar para a necessidade de $\mathrm{CP}$ poder assumir a formação em serviço, no chão da escola, cuidando do processo de indução pedagógica do professor iniciante. Evidenciamos a necessidade de um acompanhamento pedagógico de perto ao professor iniciante, se possível uma formação individualizada conforme as suas necessidades efetivas, pois para conhecê-las, se faz necessário caminhar juntos, de mãos dadas, neste percurso.

\section{REFERÊNCIAS}

ALARCÃO, I.; ROLDÃO, M. C. Um passo importante no desenvolvimento profissional dos professores: $O$ ano de indução. Revista Brasileira de Pesquisa sobre Formação Docente, Belo Horizonte, v. 06, n. 11, p. 109-126, ago./dez. 2014.

ALMEIDA, L. R. O Relacionamento Interpessoal na Coordenação Pedagógica. In: ALMEIDA, L. R. de; PLACCO, V. M. N. S. (Orgs.). O 
Coordenador Pedagógico e o Espaço da Mudança. 10. ed. São Paulo: Edições Loyola, 2012a, p. 67-79.

ALMEIDA, L. R. Diretrizes para a formação de professores: uma abordagem possível. In: PLACCO, V. M. N. S.; ALMEIDA, L. R. (Orgs.). O Coordenador Pedagógico e os Desafios da Educação. 4. ed. São Paulo: Edições Loyola, 2012b, p. 9-24.

ANDRÉ, M. E. D. A. Formação de professores: a constituição de um campo de estudos. Educação, Rio Grande do Sul, v.33, n. 3, p.174-181, 2010.

ANDRÉ, M. E. D. A. O que é um estudo de caso qualitativo em Educação? Educação e Contemporaneidade, Salvador, v. 22, n. 40, p. 95-103, jul./dez. 2013.

BETEGHELLI, T. G. S. A professora coordenadora na educação infantil: na composição da organização do trabalho pedagógico e da formação dos educadores. 2018. 206f. Dissertação (Mestrado em Educação), Universidade Estadual de São Paulo, Rio Claro, 2018.

CYRINO, M. Do acolhimento ao acompanhamento compartilhado: a construção colaborativa de uma proposta para o estágio curricular no curso de pedagogia. 2016. 345 f. Tese (Doutorado em Educação), Universidade Estadual de São Paulo, São Paulo, 2016.

GOUVEIA, B.; PLACCO, V. M. N. S. A. Formação Permanente, o Papel do Coordenador pedagógico e a rede colaborativa. In: ALMEIDA, L. R.;

PLACCO, V. M. N. S. (Orgs.). O Coordenador Pedagógico e a Formação Centrada na Escola. São Paulo: Edições Loyola, 2013. p. 69 - 91.

MARCELO GARCIA, C. Desenvolvimento profissional docente: passado e futuro. SISIFO Revista de Ciências da Educação, Porto, n. 8, p. 7-22, jan.-abr. 2009.

MOLLICA, A. J. P. O professor especialista iniciante: contribuições do coordenador pedagógico para seu trabalho. 2014. 247 f. Tese (Doutorado em Psicologia da Educação), Pontifícia Universidade Católica de São Paulo, São Paulo, 2014.

NÓVOA, A. Para uma formação de professores construída dentro da profissão. Revista Educación. Madrid, 2009.

PEREIRA, R. O desenvolvimento profissional de um grupo de coordenadoras pedagógicas iniciantes: movimentos e indícios de aprendizagem coletiva, a partir de uma pesquisa-formação. 2017. 251 f. Tese (Doutorado em Psicologia da Educação), Pontifícia Universidade Católica de São Paulo, São Paulo, 2017. 
REIS, P. A indução como elemento chave na formação e no acesso à profissão dos professores. Coleção Seminários e Colóquios. Conselho Nacional de Educação, Edição Eletrônica, Lisboa, 2015. Disponível em: https://www.academia.edu/19727843/A_indu\%C3\%A7\%C3\%A30_como_elem ento_chave_na_forma\%C3\%A7\%C3\%A3o_e_no_acesso_\%C3\%A0_profiss\%C3 \%A3o_dos_professores. Acesso em: 01 jun. 2020.

ROGERS, C. R. Tornar-se pessoa. São Paulo: Martins Fontes, 1997.

RONCON, C. L. A. Implicações de programas de iniciação à docência na inserção profissional de professores. 2018. 127 f. Dissertação (Mestrado em Educação), Universidade Federal de São Paulo, Guarulhos, 2018.

SANTOS, R. E. S. Formação de professores que ensinam matemática nos anos iniciais: contribuições do Programa Institucional de Bolsas de Iniciação à Docência (PIBID) na UFSCar. 2013. 107 f. Dissertação (Mestrado em Ciências Humanas). Universidade Federal de São Carlos, São Paulo, 2013.

SCHNEIDERS, P. M. Possibilidades de acompanhamento pedagógico de professores iniciantes frente aos desafios do trabalho em um instituto federal de educação, ciência e tecnologia. 2017. 211 f. Dissertação (Mestrado em Políticas Públicas e Gestão Educacional). Universidade Federal de Santa Maria, Rio Grande do Sul, 2017.

SILVA, D. C. F. O papel do coordenador pedagógico na socialização do professor iniciante na rede municipal de Andradina-SP. 2017. $164 \mathrm{f}$.

Dissertação (Mestrado em Educação). Universidade Estadual de Mato Grosso do Sul, Mato Grosso do Sul, 2017.

SILVA, M. S. L. Práticas formativas em Mato Grosso sob o olhar de professores iniciantes. 2014. 121 f. Dissertação (Mestrado em Educação). Universidade Federal de Mato Grosso, Mato Grosso, 2014.

SOLIGO, R. Todo professor mora em uma pessoa, todo aluno mora também. Pipocas Pedagógicas, GEPEC-UNICAMP, Campinas, s/d. Disponível em : <https://rosaurasoligositeoficial.files.wordpress.com/2017/04/rosaura-soligotodo-professor-mora-em-uma-pessoa-todo-aluno-mora-tambc3a9m.pdf>. Acesso em: 02 mai. 2020.

SULA, M. C.; PLACCO, V. M. N. S. O tempo, o caminho e a experiência do coordenador pedagógico da creche: as rotinas e os saberes que articulam, formam e transformam suas práticas educacionais - reflexões pós-pesquisa. In: GIMENES, N. A. S.; PASSARELLI, G. L. (Orgs.). Formando formadores para a escola básica do século XXI. Campinas, SP: Pontes Editores, 2018.

SULA, M. C. O tempo, o caminho e a experiência do coordenador pedagógico da creche: as rotinas e os saberes que articulam, formam e transformam suas práticas educacionais. 2016. 206 f. Dissertação (Mestrado 
Profissional em Educação). Pontifícia Universidade Católica de São Paulo, São Paulo, 2016.

TELES, N. C. G. Formação Continuada e desenvolvimento profissional de professores da educação básica que participam de um programa de inserção profissional. 2019. 227 f. Tese (Doutorado em Psicologia da Educação). Pontifícia Universidade Católica de São Paulo, São Paulo, 2019.

WONG, H. K. Induction Programs That Keep New Teaching and Improving.

NASSP Bulletin, v. 88, n. 638, p. 41-58, Mar. 2004.

Recebido em: 27 de janeiro de 2021.

Aprovado em: 16 de março de 2021.

Publicado em: 20 de abril de 2021.

(C) (1) 